\title{
Impact assessment in the European Union: Lessons from a research project ${ }^{1}$
}

\author{
Claire A. Dunlop, University of Exeter, UK
}

Claudio M. Radaelli, University of Exeter, UK

In this article, we present some major lessons drawn from a recently completed research project. Our research dealt with ex-ante evaluation, mainly impact assessment (IA). We shed new light on research questions about the control of bureaucracy, the role of IA in decision-making, economics and policy learning, and the narrative dimension of appraisal. We identify how our findings stand in relation to conventional arguments about these issues, and reflect on their normative implications. We finally reason on the possible extensions of our arguments to the wider field of policy evaluation, connecting IA and ex-post evaluation.

Keywords: evaluation, European Union (EU), impact assessment, policy appraisal, policy instruments

In the late 1990s, the rare studies of ex-ante policy evaluation found it difficult to report on any concrete development within the European Commission outside financial planning and the structural funds. Take for example Pelkmans, Labory, Majone ${ }^{2}$ who were unable to report on the number of fiches d'impact (the instrument used at the time to appraise the likely effects of policy proposals of the Commission), what they contained, and who was using them. But today this topic has gained a stable place on the research agenda of social scientists, for example in political science ${ }^{3}$ and law. ${ }^{4}$ As Smismans' notes in the introduction

\footnotetext{
${ }^{1}$ The article arises out of original research funded by the European Research Council (ERC) project Analysis of Learning in Regulatory Governance (ALREG) (\#230267). We thank Christie Smith for all her help in formatting the work and the editor of this special issue and two anonymous referees for their insightful comments made on earlier drafts of the work. The usual disclaimer applies.

2 Jacques Pelkmans, Sandrine Labory S and Giandomenico Majone, "Better EU regulatory quality: Assessing current initiatives and new proposals", in Giampaolo Galli and Jacques Pelkmans (eds.), Regulatory Reform and Competitiveness in Europe, Volume 1: Horizontal Issues (Cheltenham: Edward Elgar, 2000), pp. 461 et sqq.

${ }^{3}$ Camilla Adelle, Andrew Jordan and John Turnpenny, "Proceeding in Parallel or Drifting apart? A Systematic Review of Policy Appraisal Research and Practices", 30 Environment and Planning C: Government and Policy (2012), pp. 401 et sqq.; Claire A Dunlop, "The Temporal Dimension of Knowledge and the Limits of Policy Appraisal: Biofuels Policy in the UK", 43 Policy Sciences (2010), pp. 343 et sqq.; Claire A Dunlop, Oliver Fritsch and Claudio M Radaelli, "The Appraisal of Policy
} 
to this volume, ${ }^{5}$ nowadays research on ex-ante policy appraisal falls within the wider field of policy evaluation, broadly defined to cover the whole policy cycle - from ex-ante analysis to ex-post appraisal. On this core idea, the European Union (EU) is in synch with the Organisation for Economic Cooperation and Development (OECD). The OECD has recently adopted an integrated framework for policy evaluation ${ }^{6}$ where several concepts and even indicators developed in the practice of ex-ante assessment are transferred to ex-post analysis, with the aim of encouraging a common evaluative approach to regulation and legislation more generally.

This reflects the politics of attention in regulatory evaluation: in the 1990 s, only a few Member States were pushing a reluctant Commission to activate systematic initiatives for the integrated appraisal of EU legislation, be it ex-ante or ex-post. These years witnessed the emergence of the concepts of business impact assessment, compliance cost measurement, and better law-making, but there was no integrated response from the EU institutions. ${ }^{7}$ Radaelli reviewed in 1999 the initiatives for ex-ante evaluation of policy Appraisal - Learning About Impact Assessment", 149 Revue Française D'Administration Publique (2014), pp. 163 et sqq.; John Turnpenny, Måns Nilsson, Duncan Russel et al., "The policy and politics of policy appraisal: Emerging trends and new directions", 16 Journal of European Public Policy (2009), pp. 640 et sqq.

${ }^{4}$ Anne CM Meuwese and Stijn van Voorst, "Impact Assessment in Legal Studies", in Claire A Dunlop and Claudio M Radaelli (eds.), Handbook of Regulatory Impact Assessment, (Cheltenham: Edward Elgar, forthcoming).

${ }^{5}$ Stijn Smismans, "Introduction to this volume", European Journal of Risk Regulation (2015) THIS VOLUME DETAILS

${ }^{6}$ OECD, Framework for Regulatory Policy Evaluation, (Paris: OECD Publications, 2014); see Anne CM Meuwese, Michiel Scheltema and Lynn van der Velden, "The OECD Framework for Regulatory Policy Evaluation: an initial assessment", European Journal of Risk Regulation, this volume details.

${ }^{7}$ Julie Froud, Rebecca Boden, Anthony Ogus et al., Controlling the Regulators, (Basingstoke, Hampshire: Macmillan, 1998). 
proposals (excluding structural funds and financial planning) and concluded that the various pilot initiatives with policy instruments had not produced an integrated template and a coherent instrumentation - much ado about nothing. ${ }^{8}$

Now there is a full range of initiatives for policy evaluation in the so-called smart regulation agenda of the EU and in the Member States. This evaluation turn has affected policy-makers' understandings of the nature of EU law and its role in larger architectures for integrating policy and law, as shown by Smismans. ${ }^{9}$ Even the language and the labels used by policy-makers accompany this rise in attention - alongside the by-now traditional impact assessment of legislative and non-legislative proposals of the European Commission, we see an emerging policy agenda concerned with ex-post evaluation and post-implementation review, including projects to re-fit European legislation to changing structural conditions ${ }^{10}$ and carry out ex-post evaluations. ${ }^{11}$ The attention for the problems created by administrative obligations has remained high since 2004, with several 'wars' on red tape endorsed by successive EU presidencies, the Commission, and stakeholders. ${ }^{12}$ All this activity is supposed to connect with the more established tradition of evaluation of

\footnotetext{
${ }^{8}$ Claudio M Radaelli, "Steering the Community regulatory system: the challenges ahead", 77 Public Administration (1999), pp. 855 et sqq.

${ }^{9}$ Stijn Sismans, "From Harmonization to Co-ordination? EU Law in the Lisbon Governance Architecture", 18 Journal of European Public Policy (2011), pp. 504 et sqq.

${ }^{10}$ Commission Communication on the Regulatory fitness and performance programme (REFIT): State of play and outlook, COM(2014)368.

${ }^{11}$ Commission Communication on Strengthening the foundations of Smart Regulation - improving evaluation, Communication, COM(2013)686.

${ }^{12}$ Paola Coletti, Evidence for Public Policy Design: How to Learn from Best Practice, (Basingstoke: Palgrave, 2013).
} 
expenditure programmes, to create a coherent evaluation culture across EU institutions this, at least, is the stated aim of the Commission.

In short, a neglected issue has become familiar territory for researchers and policymakers. The year 2002 signals the moment when the Commission took the commitment to use a single integrated template (Impact Assessment, IA) to evaluate new proposals (beyond what was already done for expenditure programmes), to implement common standards for consultation, and to articulate an action plan for better regulation. ${ }^{13}$ After almost fifteen years, researchers have sufficient evidence to review the experience with ex-ante evaluation and IA in particular. We undertake this task by drawing lessons from a four-year project on Analysis of Learning in Regulatory Governance, ${ }^{14}$ funded by the European Research Council. In this contribution, we focus on some important conceptual findings rather than data on individual policy instruments or episodes to contribute to the research questions on policy evaluations that inform our special issue. Consequently, we will draw on a number of articles produced within ALREG - the reader can find evidence and data therein - and concentrate on the conceptual lessons. In the remainder, our main concern is the EU level, but when necessary we add observations on the situation is the Member States, since the two levels co-exist and interact. In the conclusions we elaborate on the implications of

\footnotetext{
${ }^{13}$ Commission Communication on Impact assessment, COM(2002)276; Commission Communication Towards a reinforced culture of consultation and dialogue. General principles and minimum standards for consultation of interested parties by the Commission, COM(2002)704; Commission Communication Action plan: Simplifying and improving the regulatory environment, COM(2002)278.

${ }^{14}$ Details available on the Internet at $<$ (http://socialsciences.exeter.ac.uk/politics/research/centres/ceg/research/projects/alreg/> (last accessed on 28 January 2015).
} 
our lessons for a critical research agenda in this field ${ }^{15}$ and for our wider theoretical understanding of the politics of bureaucracy, learning and diffusion of policy instruments.

\section{What is impact assessment for?}

\section{Control instrument, tool of bureaucratic empowerment or just a symbol?}

At the outset, any appraisal of the experience with IA and smart regulation in the EU has to start with a theoretical proposition about the rationale for policy adoption. ${ }^{16}$ This rationale lies in delegation theory. The original intuition by McCubbins, Noll and Weingast ${ }^{17}$ was that by saddling United States (US) agencies with formal obligations to carry out and publish regulatory analysis, information asymmetry would be reduced, taking the informational advantage away from the agency. Ex-post evaluation follows a similar control rationale, although to intervene on an agency when the policy programme is evaluated may be too late. Early warnings via administrative procedures during the drafting process, in contrast, are effective because they capture an agency's deviation 'prior to the agency's implementation of a change in policy'. ${ }^{18}$ Damonte, Dunlop and Radaelli ${ }^{19}$ generalise this

\footnotetext{
${ }^{15}$ See John Turnpenny, Claudio M Radaelli, Andrew Jordan et al., "The policy and politics of policy appraisal: Emerging trends and new directions", 16 Journal of European Public Policy (2009), pp. 640 et sqq.

${ }^{16}$ Fabrizio De Francesco, Transnational Policy Innovation: The OECD and the Diffusion of Regulatory Impact Analysis, (Colchester: ECPR Press, 2013).

${ }^{17}$ Mathew D McCubbins, Roger G Noll and Barry R Weingast, "Administrative procedures as instruments of political control", 3 Journal of Law, Economics, and Organization (1989), pp. 243 et sqq.

${ }^{18}$ Ibid., at p. 481, emphasis in original; David Epstein and Sharyn O'Halloran, "Asymmetric Information, Delegation, and the Structure of Policy-making", 11 Journal of Theoretical Politics (1999), pp. 37 et sqq.
} 
argument to all instruments based on a fire-alarm logic: regulatory analysis is a fire alarm instrument that affected interests can pull at an early stage when a regulatory proposal damages them. IA enfranchises these interests and gives a voice to affected industries, constituencies of support for the elected politicians, and experts like economists, so that bureaucratic drift is limited. ${ }^{20}$

Indeed, much of the US literature on IA stems from this rationale, with questions on the nature of control exercised by the Office for Information and Regulatory Analysis (OIRA) on federal executive agencies. ${ }^{21}$ Other US projects have looked at the different ways in which bureaucratic control can be effectively exercised by pressure groups. ${ }^{22}$

Briefly, it has become customary to think of evaluation, especially in IA, as policy instrument for the control of bureaucracy. The Commission being a bureaucracy, the extension to the European case seems straightforward. But, is it? Indeed, when our team probed the different implications of the control argument in Europe, the findings have been less supportive of the control thesis. IA can be quite blunt as instrument of control of the Commission - and, turning to the domestic level, in some Member States like Denmark and

\footnotetext{
${ }^{19}$ Alessia Damonte, Claire A Dunlop and Claudio M Radaelli, "Controlling bureaucracies with fire alarms: policy instruments and cross-country patterns', 21 Journal of European Public Policy (2014), p. 1330 et sqq.

${ }^{20}$ See ibid. for the full-length explanation.

${ }^{21}$ Steven Croley, "White house review of agency rulemaking: An empirical investigation", 70 University of Chicago Law Review (2003), p.821 et sqq,; Winston Harrington, Lisa Heinzerling and Richard D Morgenstern (eds.), Reforming Regulatory Impact Analysis, (Washington DC: Resources for the Future, 2009); Stuart Shapiro, "Evaluating the benefits and costs of regulatory reforms: What questions need to be asked?", 31 Evaluation and Program Planning (2008), p.223 et sqq.; William F West, "The institutionalization of regulatory review: Organizational stability and responsive competence at OIRA", 35 Presidential Studies Quarterly (2005), p.76 et sqq.

${ }^{22}$ Susan Webb Yackee, "Sweet-Talking the Fourth Branch: the Influence of Interest Group Comments on Federal Agency Rulemaking", 16 Journal of Public Administration Research and Theory (2006), pp. 103 et sqq.
} 
Sweden there isn't evidence for the classic manifestations of bureaucratic control. ${ }^{23}$ In another ALREG paper, Radaelli and Meuwese ${ }^{24}$ conclude that IA has increased capacity for operational and strategic management within the Commission, thus effectively empowering the bureaucracy, rather than controlling it. Other projects have shown that IA in some EU Member States has symbolic properties - a veneer of rationality on a thick web of informal decision-making procedures and policy formulation conventions, hardly affected by the formal requirements of ex-ante appraisal. ${ }^{25}$ For some Member States, the issue is most likely the absence of analytical and institutional capacity. ${ }^{26}$ Without capacity, the whole idea of using detailed information to control bureaucracies via fire-alarm instruments cannot possible work.

All this leads us to conclude that we might have been inspired by the wrong theory: control may be a correct lens for the US, but in Europe either there is little capacity to control, or, simply, control is not the main effect of implementation. Arguably, bureaucracies like the Commission are empowered by IA, whilst national bureaucracies use IA as signal and symbol when they do not have analytical capacity to manage this policy

\footnotetext{
${ }^{23}$ Claudio M Radaelli, "Rationality, Power, Management and Symbols: Four Images of Regulatory Impact Assessment", 33 Scandinavian Political Studies, (2010), pp. 164 et sqq.; on ex-ante appraisal in the domain of sustainable development see Duncan Russel and John Turnpenny, "The politics of sustainable development in UK government: what role for integrated policy appraisal?", 27 Environment and Planning C: Government and Policy (2009), pp. 340 et sqq.

${ }^{24}$ Claudio M Radaelli and Anne CM Meuwese, "Hard Questions, Hard Solutions: Proceduralisation through Impact Assessment in the EU", 33 West European Politics (2010), pp. 136 et sqq.

${ }^{25}$ Julia Hertin, Andrew Jordan, John Turnpenny et al., "Rationalising the policy mess? Ex ante policy assessment and the utilisation of knowledge in the policy process", 41 Environment and Planning $A$ (2009), pp. 1185 et sqq.; Turnpenny et al., "Policy and politics of policy appraisal", supra note 15, at p. 5.

${ }^{26}$ John Turnpenny, Måns Nilsson, Duncan Russel et al., "Why Is Integrating Policy Assessment So Hard? A Comparative Analysis of the Institutional Capacities and Constraints", 51 Journal of Environmental Planning and Management (2008), pp. 759 et sqq.
} 
instrument. Normatively, the empowerment effect may or may not be desirable. It is desirable if we think that accountability in multi-level systems needs high bureaucratic capacity rather than weak bureaucratic organisations. It is not desirable if we think that an empowered European Commission can make regulatory trade-offs disguised as technical management rather than discussed in terms of constitutional values - an issue that is explored in Radaelli and Meuwese. ${ }^{27}$

\section{An instrument for decision-making processes?}

A second finding we wish to discuss concerns the role of IA in decision-making processes. The guidelines on IA published by the member states and the Commission present IA as ex-ante evaluation tool that supports the decision-making process. In a recent resolution, the European Parliament ${ }^{28}$ reiterated this position arguing it is "convinced that IAs are an important means of supporting the decision-making in all EU institutions and an important part of the better regulation process; recognises, nevertheless, that IAs cannot be substitutes for political evaluation and decisions". Put differently, IA should assist the final decision on a proposal - that is, the decision taken by the College of the Commission, but also decisions concerning substantive amendments to draft legislation introduced by the EP and the Council. The European Parliament lamented that the scope of IA may no longer mirror the proposals adopted when these proposals are altered at a final stage once

\footnotetext{
${ }^{27}$ Claudio M Radaelli and Anne CM Meuwese, "How the regulatory state differs. The constitutional dimensions of rulemaking in the European Union and the United States", XLII Rivista Italiana di Scienza Politica (2012), pp. 177 et sqq.

${ }^{28}$ European Parliament Motion for a Resolution on the Revision of the Commission's impact assessment guidelines (2014), point 6, available on the internet at: $<$ http://www.europarl.europa.eu/sides/getDoc.do?type=MOTION\&reference=P8-RC-20140311\&language $=\mathrm{EN}>$ (last accessed on 29 January 2015).
} 
submitted for approval by the College. The EP therefore requested in its resolution "that the IA should be updated to ensure continuity between matters considered in it and any proposals finally adopted by the Commission". ${ }^{29}$ The relationship with decision-making is slightly ambiguous, because to update an IA, in practice, may mean to retrofit ex-ante evaluation to match the political decision taken by the College - as well as the more benign but arguably unrealistic interpretation of carrying out new analysis to check if the final political decision still delivers net benefits.

The College of Commissioners is not supposed to react mechanically to the conclusions of an IA, and reject or support a proposal automatically. The same principle applies to the EP and the Council when substantive amendments are introduced. But neither are Commissioners, MEPs and Council officers supposed to simply take note of the IA and treat it as one of the many inputs to decision-making. In short, the decisional value of IA has captured the attention of policy-makers. This is the reason why stakeholders lament that very few IAs conclude with a rejection of a possible policy intervention by the Commission. The average IA does not challenge the 'priors' of the Commission - this is the polemical claim - but supports them. The European Parliament in the Niebler report ${ }^{30}$ complained that there is insufficient oversight of the IAs of the Commission. This is because the oversight body (the Impact Assessment Board) is made up of high-level Commission officers and is staffed by the Secretariat General - indeed the Juncker Commission signalled its intention to open up the board to external expertise. ${ }^{31}$ Overall, these critical opinions

\footnotetext{
${ }^{29}$ Ibid., point 8.

${ }^{30}$ European Parliament Report on Guaranteeing Independent Impact Assessments, Committee on Legal Affairs A7-0159/2011.

${ }^{31}$ See European Commission Press Release "President Juncker appoints Dr Edmund Stoiber Special Adviser for Better Regulation; First Vice-President Timmermans announces reform of the Impact
} 
claim that the IA ought to be a strong tool for decision-making, but in the real world it may be used exclusively to support a given policy choice.

Empirical evidence sheds different light on the decisional value of IA. Ex-ante evaluation is not necessarily used to 'speak the truth to power' - shown the case studies in Meuwese's project. ${ }^{32}$ In our project, we found that the IA is not a decisional tool, but its role can be to lay out the evidence-based case for a certain policy preference of the Commission. ${ }^{33}$ This preference is not necessarily the output of IA. It can be pre-defined, or it can come out of last minute discussions within the College. And yet, IA still improves policy choice - even if it does not identify what this choice should be. The improvement consists of empirical analyses of the effects of the choice, on how the chosen option can be modulated across time and sectors, and on the deeper consideration of administrative compliance costs and implementation problems. Consultation reveals new issues to be taken on board. Importantly, the process of carrying out an IA obliges the Commission to give empirical and conceptual reasons for policy choice - whether the Commission would have gone for the same choice with our without IA is not the fundamental issue.

Indeed this argument does not mean that the IA has limited usage. The IA has an effect after its publication, that is, post-decision. After its publication, the IA has a postdecisional role when it is used by the EP or later in the process by the European Court of

Assessment Board", available on the Internet at http://europa.eu/rapid/press-release IP-142761 en.htm (last accessed 30 January 2015).

${ }^{32}$ Anne CM Meuwese, Impact Assessment in EU Lawmaking, (The Hague: Kluwer Law International, 2008).

${ }^{33}$ Claire A Dunlop, Martino Magetti, Claudio M Radaelli, et al., "The many uses of regulatory impact assessment: A meta-analysis of EU and UK cases", 6 Regulation \& Governance (2012), pp. 23 et sqq. 
Justice. ${ }^{34}$ Majone ${ }^{35}$ has shown the various effects of post-decisional analysis, exactly mentioning the use in Courts among others. It is also realistic to consider what the IAs of the Commission are about: on average, they are not about 'yes' or 'no' decisions like 'shall we regulate the environmental consequences of steel production or not' - they are about the mode, timing and details of a certain design of policies that have been elaborated via studies, working parties and other preparatory activities through the years.

Although we argue that the 'yes/no' straightforward decisional role is weak, there are effects on the Commission's decisional process that seem empirically important. Consider the following. Within the Commission, the preparation of IAs has made policy formulation more complicated than before. The IA steering groups of the Commission include all the Directorates General affected by a proposal plus the Secretariat General with a co-ordination role. IA as process has brought more actors into the process of preparing policy proposal. In an article by Radaelli and Meuwese ${ }^{36}$ we argued that the preparation of IAs has limited the silos mentality of the past. It forces the different interests represented by the officers (from different DGs) involved in the IA steering groups to dialogue and coordinate, using evidence-based argumentation. ${ }^{37}$ Thus, in a sense, making things complicated is a virtue of IA because it allows the Commission to exploit the benefits of partisan mutual adjustment. Evidence-based bargaining within the Commission's units

\footnotetext{
${ }^{34}$ Alberto Alemanno, "Impact assessment and Courts", in Claire A. Dunlop and Claudio M. Radaelli (eds.), Handbook of Impact Assessment, (Edward Elgar, forthcoming).

${ }^{35}$ Giandomenico D Majone, Argument and Persuasion in the Policy Process, 1st ed. (New Haven and London: Yale University Press, 1989).

${ }^{36}$ Radaelli and Meuwese, "Hard Questions, Hard Solutions", supra note 24, at p. 7.

${ }^{37}$ The same findings appear in Erica Melloni, "Ten Years of European Impact Assessment: How It Works, for What and for Whom", 9 World Political Science Review (2013), pp. 263 et sqq.
} 
working in the IA steering groups is a way to learn from information brought into the policy process by officers with different policy preferences and interests. ${ }^{38}$ To conclude, our project provides content to the ambiguous proposition that the IA should support decisions without being a substitute for political decision-makings. Its supporting role is about improving the quality of the policy formulation process within the Commission via partisan mutual adjustment and, beyond the Commission, in post-decisional analysis.

\section{How 'good' is impact assessment?}

\section{Economics logic and modes of learning}

How 'good' is a policy instrument? There are different answers to this question. In the case of ex-ante evaluation, we can consider different criteria such as whether the IA is used by decision-makers and stakeholders ${ }^{39}$ or carries out the tests prescribed in the guidelines. ${ }^{40}$ More fundamentally, we can raise issues about the robustness of the underlying rationale - the intrinsic social scientific robustness of a given policy instrument for evaluation. The literature on policy instruments ${ }^{41}$ argues that the instruments adopted

\footnotetext{
${ }^{38}$ Radaelli and Meuwese, "Hard Questions, Hard Solutions", supra note 24, at p. 7.

${ }^{39}$ Dunlop et al., "The many uses of regulatory impact assessment", supra note 31, at p. 10; Hertin et al., "Rationalising the policy mess?", supra note 25, at p.7; Lorna Schrefler, "The Usage of Scientific Knowledge by Independent Regulatory Agencies", 23 Governance (2010), pp. 309 et sqq.

${ }^{40}$ Robert W Hahn and Patrick M Dudley, "How Well Does the Government Do Cost-Benefit Analysis?", Working Paper 04/01, (AEI Brookings Joint Center for Regulatory Studies, 2004); Andrea Renda, Impact Assessment in the EU: The State of the Art and the Art of the State, (Brussels: Centre for European Policy Studies, 2006); Caroline Cecot, Robert Hahn, Andrea Renda et al., "An Evaluation of the Quality of Impact Assessment in the European Union with Lessons for the US and the EU", 2 Regulation \& Governance (2008), pp. 405 et sqq.

${ }^{41}$ Pierre Lascoumes and Patrick Le Galès, "Introduction: Understanding Public Policy through Its Instruments-From the Nature of Instruments to the Sociology of Public Policy Instrumentation", 20 Governance (2007), pp. 1 et sqq.
} 
by governments are carriers of specific economic ideas or economic theories. There is no doubt that economics is the main rationale evoked in the literature on ex-ante policy formulation. Actually it is exactly for this reason - that is, IA as vehicle of specific economic lenses on a wide range of policy issues - that ex-ante appraisal has been criticized by those who oppose the economic quantification of environmental issues, human rights and other types of policy problems. ${ }^{42}$

We suggest a different interpretation. True, policy instruments are carriers of economic ideas. But they also carry a view of the world which public managers face: this world can be a world of rational-synoptic agents, that scan a high number of options rootand-branches until the find the most efficient one, or a world of bounded rationality. Thus, alongside an economic worldview, policy instruments also contain a set of assumptions about how public managers learn from evidence.

In Coletti and Radaelli ${ }^{43}$ we follow this dual approach (economic ideas and assumptions about learning) and argue that a given regulatory instrument contains both an economic rationale and a learning model, or a 'logic' of how and what constellations of actors learn by using the instrument. We then examine IA and the Standard Cost Model (SCM) used for the identification of the costs of administrative obligations. ${ }^{44}$ They are both used in policy formulation at the EU level, whilst some member states carry out ex-ante evaluation with the SCM but do not engage with the wider IA. If we look only at the

\footnotetext{
${ }^{42}$ Douglas A Kysar, Regulating from Nowhere: Environmental Law and the Search for Objectivity, (New Haven and London: Yale University Press, 2010).

${ }^{43}$ Paola Colettti and Claudio M Radaelli, "Economic Rationales, Learning, and Regulatory Policy Instruments", 91 Public Administration (2013), pp. 1056 et sqq.

${ }^{44}$ See Jacopo Torriti, "The Standard cost model: when better regulation fights against red-tape" in Stephen Weatherill (ed.), Better Regulation, (Oxford: Hart Publishing, 2007).
} 
economic robustness of the two instruments, IA should always be preferred to the SCM. The latter is concentrated on a narrow category of costs, ${ }^{45}$ it does not look at benefits, and may lead to inefficient policy choices - simply put, economically wrong evaluations of option. However, if we flip the coin and consider the robustness of the two policy instruments in terms of their learning models, the conclusion changes. Economically rudimentary forms of appraisals like the SCM contain more realistic and effective learning models than IA. In Coletti and Radaelli ${ }^{46}$ we explain how the SCM has triggered learning processes in some member states, leading to approaches to map the regulatory process from the point of view of the stakeholders, to the inclusion in regulatory reform programmes of stakeholders who had been at the margin until now, to stronger linkages between ICT initiatives in the public sector and regulatory reform, and to the consideration of wider compliance costs. The conclusion is straightforward: when we discuss whether an instrument for policy evaluation will work or not, we should consider both the robustness of its underlying economic ideas and its assumptions about learning and rationality.

\section{The narrative components}

Another way of looking at why regulators write IAs is to think about policies as theories. ${ }^{47}$ A policy proposal is a set of hypothesis about cause-and-effect relations. It follows that IA is the place where these cause-and-effect relations are spelled out. In other words, the IA portrays the causal structure of a given policy proposal. Since they are used to

\footnotetext{
${ }^{45}$ Dieter Helm, "Regulatory Reform, Capture, and the Regulatory Burden", 22 Oxford Review of Economic Policy (2006), pp. 169 et sqq.

${ }^{46}$ Coletti and Radaelli, "Economic Rationales", supra note 41, at p. 13.

${ }^{47}$ Stuart S Blume, "Policy as Theory: A Framework for Understanding the Contribution of Social Science to Welfare Policy", 20 Acta Sociologica (1977), pp. 247 et sqq.
} 
make the case for a given proposal, IAs are more than repositories of empirical evidence. They are not review essays. Their role is to coordinate discourse within the Commission, where the IA steering groups, as explained above, engage in partisan mutual adjustment; and to communicate to the broader public of MEPs, Council working groups, stakeholders and delegates from the Member States. The IAs have a persuasion function and are written with specific readers over the shoulders of the Commission's officers.

These considerations invite a novel exploration of IA by adopting the tools and methods of discourse analysis. Given their causal structure ('we have to do $X$ to reach $Y$ because $X$ will produce this and that effect leading to $Y^{\prime}$ ), IA can be studied as causal narratives of public policy. We followed this approach in Radaelli, Dunlop and Fritsch. ${ }^{48}$ We found that not only do the IAs contain 'policies as theories' and often engage with policy narratives. This role of the Commission as 'narrator' had not been explored in the past, although the use of IA as communication and persuasion tool features prominently in our own discussions and interviews with policy-makers. Experiments in behavioural economics point to the importance of social trust in the narrator. ${ }^{49}$ Given the current state of trust in EU institutions and the credibility issues surrounding the Juncker Commission, it seems risky (for the Commission) to engage in 'grand narratives' and evoke value. And identities too, e.g. who 'Europeans' are, what the nature of the Commission is, who is better placed to do what in relation to a given policy issue. And yet, our analysis shows that IAs are used to reiterate issues of identity and values that, although they may appear already in the Treaty, are taken to their narrative conclusions in the IA. In our sample, we found several

\footnotetext{
${ }^{48}$ Claudio M Radaelli, Claire A Dunlop and Oliver Fritsch, "Narrating impact assessment in the European Union", 12 European Political Science (2013), pp. 500 et sqq.

${ }^{49}$ E.g. Robert B Cialdini, Influence: The Psychology of Persuasion (New York, NY: Harper, 2007).
} 
propositions about what 'European values' are and what ought to be in the EU and beyond. The fact that values and identities are developed within bureaucratic documents like the IAs and not in constitutional discussions may be disturbing normatively. Pragmatically, it signals a recurrent problem with the behaviour of the Commission already spotted by Laura Cram: ${ }^{50}$ when trust and credibility are low, the Commission does not go back to its core business and show concrete results. Instead, it tends to scale up in ambition and engage with grandiose narratives of 'governance'. Viewed in this light, the narrative features of IA may be part of a bigger problem.

\section{Conclusion}

In this article, we have reflected on a number of major findings from our recent project. Whilst it is customary to think of IA as control instrument, our research suggests that this instrument may strengthen the bureaucracy in Brussels. We cannot say whether increased capacity for strategic and operational policy design and management within the Commission leads to autonomy and 'escape from control' - definitively we need more research on the usage of IAs by the EU institutions. In another article from our project, ${ }^{51}$ we have made the case for 'equifinality': different concatenations of variables lead to outcomes like 'control' and 'learning' - hence we need a nuanced perspective on these questions.

We have also qualified the decisional role of IA. The latter contributes to the decisionmaking process, but its merit over time is most likely to lay out arguments and evidence that can be used after the decision is taken, by the EP, Courts, stakeholders and perhaps the same bureaucracies that generates the original IA and go back to the same issue years later

\footnotetext{
${ }^{50}$ Laura Cram, "Governance 'to Go': Domestic Actors, Institutions and the Boundaries of the Possible", 39 Journal of Common Market Studies (2001), pp. 595 et sqq.

${ }^{51}$ Dunlop et al., "The many uses of regulatory impact assessment", supra note 31, at p. 10.
} 
in the context of another IA. To illustrate, the Commission has dealt with the issue of regulation of trade from seals' fur in different regulatory interventions during the last ten years. $^{52}$

Further, we argued that IAs have a narrative function that accompanies, without necessarily substituting, the function of providing economic analysis of the proposals under consideration. This narrative function extends to identity building and the definition of values - something that may have desirable or undesirable normative implications depending on how we approach constitutional politics in the EU. Finally, in terms of policy design diffusion and international transfer, we have argued that best practices hinder instead of facilitating transfer and the social construction of lesson-drawing. The implementation and diffusion of IA is sensitive to the learning logic encapsulated in this policy instrument - another argument that rectifies our conventional views.

Throughout the article, we have supported our modifications of propositions and interpretations that are quite diffuse in the debate on ex-ante evaluation - a sort of conventional wisdom. Thus, why did we find that the conventional interpretative lens may be wrong? One reason is the logic of scientific inquiry. The vast majority of research that defined the 'theory' of IA in the early days was produced by scholars with data from the US case. It is sensible to suggest that some conclusions drawn on the US case may not be valid when we consider Europe. What we thought was a general theoretical argument about IA was instead a local theory, valid only in certain places and times.

Another reason is the role played by international organisations and policy-makers in distilling lessons and conventional propositions that assist their communication, the design

\footnotetext{
${ }^{52}$ Radaelli, Dunlop and Fritsch, "Narrating impact assessment", supra note 46, at p. 15.
} 
of guidance for IA, training and the diffusion of economic analysis in government and at the Commission. Because of these objectives (diffusion, training, communication, implementation), complex causal phenomena are reduced to simple propositions that can be somewhat 'sloganized'. Some of them have intuitive value, like the logic of best practice, and are heuristically attractive. With this article we have shown the dangers of relying on assumptions that are not exposed to critical empirical and theoretical challenge.

One question for the readers of this special issue is whether the arguments we aired can be extended to the ex-post evaluation of legislation. Obviously while the Commission has produced IAs for more than a decade, the experience of the Commission with legislative evaluation carried out ex-post is much more fragmentary and we lack a body of empirical research. We can only talk at the conceptual level. Conceptually, indeed, if appraisals strengthen the bureaucracy instead of controlling it, the argument could apply to both exante and ex-post. The observations about the decisional role of evaluations can extend to ex-post - the Commission may not use evaluations to terminate legislation but there may be other effects on the decisional process and post-decisional effects. The remarks on narration and best practice are conceptually transferrable to the ex-post phase of evaluation, and learning may impact on economic models' usage both in the ex-ante and the ex-post case. Of course, this does not suggest any conclusion absent empirical analysis but it invites an integrated research agenda for the whole life cycle of evaluation. 